\title{
Agent Oriented Methodology for Crime Modelling and Simulation
}

\author{
Cheah Wai Shiang, Sim Yee Wai, Nurfauzabt Jalia, Muhammad Asyraf bin Khairuddin
}

\begin{abstract}
Agent-oriented methodology (AOM) is a comprehensive and unified agent methodology for agent-oriented software development. The potential of Agent Oriented Methodology has been revealed in domains like collaborative technology, video surveillance, and economics. However, it has not been explored in crime modelling and simulation. Although AOM is claimed to be able to cope with a complex system development, it is still not yet determined up to what extent this may be true. Therefore, it is vital to investigate to validate this methodology. This paper investigates the adoption of AOM in crime modeling and simulation. The novelty of this paper is to introduce a systematic way to model crime simulation. Through the AOM simulation, it is proven that the AOM can model the complex system in crime domain with various outcomes which supported a few existing research theories such as routine activity theory. AOM can provide a wider research platform which is useful for translating theories and micro-level behavior into models and simulation that can be studied, shared, tested and enhanced.
\end{abstract}

Index Terms: Agent-oriented methodology, agent simulation, crime modelling, simulation.

\section{INTRODUCTION}

Agent Oriented Methodology [1]-[3] provides a way to represent a complex system of autonomous agents or actors and simulates the multiple potential results of these agents' behaviors and interactions between the desired agents. To date, it has been used in rural ICT study, disaster management, military training, collaborative learning [7], sustainability study [4], mathematical science and simulation [8]-[10], security[5], games[6]. An agent-oriented model is usually comprised of virtual "agents" who owns unique behavior and able to act autonomously without a central controller. They exist in a virtual environment which is often spatial. They can navigate around their environment, interact with each other and make decisions. The advantages of AOM [19], [20] over any other modeling approaches can be described as AOM captures emergent phenomena, AOM provides a natural description of a system and AOM is flexible.

Obviously, the ability of AOM being able to captures the emergent phenomena is what makes AOM greater and better than any other modeling techniques. Although AOM has been introduced since 1990s, the adoption of AOM in

Revised Version Manuscript Received on August 19, 2019.

CheahWaiShiang, Senior Lecturer, Faculty of Computer Science \& IT, UNIMAS,Malaysia.

Sim Yee Wai, Associate Professor, School of Computing and Creative Media, University College of Technology Sarawak, Malaysia

NurfauzabtJaliis a lecturer at Faculty of Computer Science and Information Technology, UNIMAS,Malaysia.

Muhammad Asyraf bin Khairuddin,Lecturer ,Faculty of Computer Science \& IT, UNIMAS, Malaysia. industry is still low. Among the reasons is the lack of case studies to support the current agent-oriented methodology as a great approach to study a complex system, specifically in crime domain. This is perhaps because many people consider them as in-transparent and unreliable (as compared to analytical or statistical method) or as an unsuitable approach for prediction. Hence, the paper is carried out to investigate the adoption of AOM in crime domain and simulation at the same time, recommend the improvement of AOM for crime modeling and simulation. We adopt the Agent oriented methodology (AOM)[11]-[16] to study the crime modelling and simulation in this paper. This paper aims to promote a new insight into how crime modelling can be benefits from the agent-oriented methodology (AOM). This is important to showcase what can work and what does not work for AOM. Thus, it can promote the AOM to a wider audience. To date, AOM has been explored in ICT4D, collaborative learning technology, video surveillance, games, sustainability modelling.

Section two presents the related work on crime modelling. This is followed by a section to present a systematic way to model a crime study through agent-oriented methodology (AOM). The simulation of the crime is presented after the modelling section. A model validation is discussed after the simulation together with the lesson learnt.

\section{RELATED WORKS}

Crime can be an extremely complex event which consists of a lot of uncertain factors. Crime is not a random event that just occurred. There is a numerous on-going research trying to explain some of the patterns underlying criminal occurrences. The statistical methods are usually used to study crime. Typically, there is one dependent variable of interest for example, crime rates and model accuracy are usually determined through statistics. However, statistical models also have its own flaws such as system complexity and inaccurate data input. For example, statistical models generally utilize simple functional relationships and fail to capture the current emotion or routines of individuals and its effect on their behavior.

The use of Agent Based Modeling and Simulation (ABMS) in the study of crime is not uncommon. The first work about Agent Based Simulation in crime domain was proposed by Brantingham in 2005 [21]. In their work, they suggested a framework how to simulate individual's activities in a 
provided space or environment using agents.

An early example if from Short et al. [22] of simulation model. The researchers consider the dynamic properties of criminal problem areas utilizing a model that reproduces private robbery on a lattice whose cells speak to house areas with various degrees of engaging attraction to the criminal. The attractiveness here represents the incentives for the criminals. High attractiveness means higher impetuses for the criminal which is a more prominent inspiration to the criminal to perpetrate wrongdoing. The attractiveness or engaging quality of any house is given by a characteristic segment in addition to a dynamic one dependent on the crime rate in the prompt territory and fusing the "broken window effect" which proposes that areas that have just been burgled have a more noteworthy probability of being burgled once more [23]. In view of this model, an individual-based approach of burglary utilizing the PECS framework (Physical Conditions, Enthusiastic State, Subjective Capacities, and Societal position) has been displayed. This PECS framework highlights on modeling human behavior by incorporating a person's physical condition, emotion, cognitive capabilities and social status.

Birks, Townsley, and Stewart [24] present another AOM variant of residential burglary. They study on how the theoretical propositions, for example, routine activity approach, crime pattern theory impact offending patterns by a series of simulated tests and rational choice perspective. They found that these propositions provide a generative explanation for several independent characteristics of crime. Liu et al. focus on developed a crime simulation model based on the routine activities theory and street robbery experiment [25] which proposed that in order for a crime to be committed there must offenders, targets, and the absence of guardian. Groff et al. [26] had done similar work by applying crime simulation which supported highly on the basic premise of routine activity theory. The result of the research proposes that street crime will increment as people spend more time away from home. In this sense, it suggested that when individuals are away from home, it has no guardian. The individual can be focused on effectively which fundamentally supported the routine activities theories. In the same context, Melo, Belchior, and Furtado [27] develop another model that simulates agents' physical reorganization. This simulation uses police patrol routes as the analyzed variable. The result of the simulation shows that by changing the routes regularly, it helps to reduce the number of offences However, they did not include the costs and travel times as condition in the research, which could render it impractical in real life.

Although agent-oriented models and simulation are introduced, there is neither systematical way or methodology approach for crime modelling and simulation. Hence, it is worth to study and present in this paper.

\section{AGENT ORIENTED METHODOLOGY FOR CRIME MODELLING AND SIMULATION}

This section presents the study of adopting agent-oriented methodology for crime modelling and simulation. The agent-oriented methodology starts with goal modelling. This is followed by role modelling, domain model, organization model, agent-role mapping, scenario model, interaction model, knowledge model and behavior model.

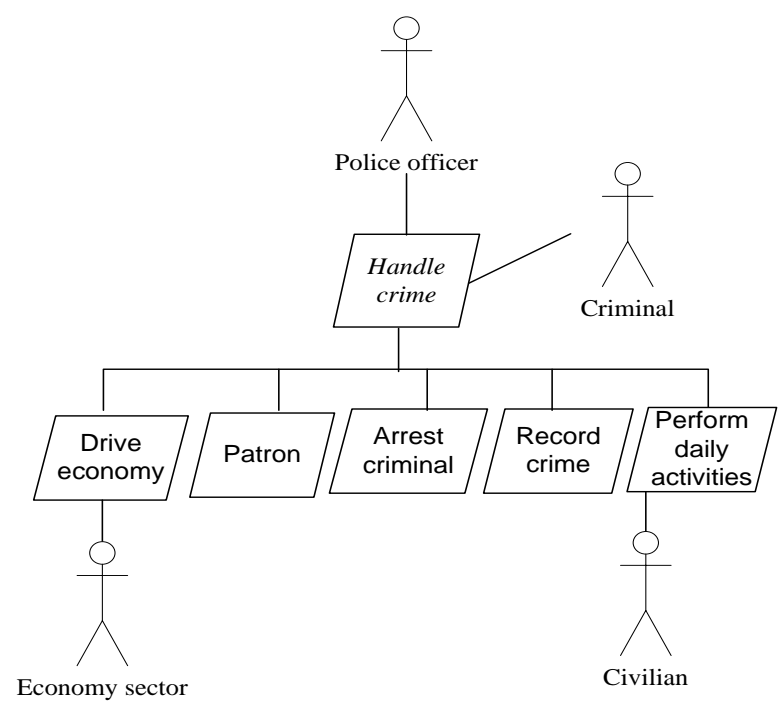

Fig. 1. Goal model for crime handling

Goal model:

Fig. 1 shows the goal model for crime handling. Goal model describes the purpose of the system (e.g. system functionality) at a higher level of abstraction. The notion of goal provides an overview of the functionalities that should be achieved by an agent system. Goals can be divided into sub-goals. For example, the goal of text extraction can be subdivided into the sub-goals of parser setting, generating training set, parsing, validating, and handling local storage. In addition to functional goals, there are quality goals that represent non-functional requirements for the system. Achieving a goal consumes resources and a goal is related to a role which indicates the actor or agent that is involved in achieving the goal [28].

In our case study, they are four actors for crime handling. The actors are police officer, criminal, economy sector and civilian. To handle crime, they are five important sub-goals that need to be achieved or performed. The sub-goal is 'patron', 'arrest criminal', 'record crime', 'perform daily activities' and 'drive economy'.

Role model:

A role model describes the role played within an organization. A role model is represented as a role schema which consists of the following elements: role name, role description, responsibilities, and constraints. In an organization, people play roles or hold positions to perform tasks. A position is required to subsume common tasks and subtasks under it. Normally, a role may be played by more than one agent and a role is assigned to achieve a certain goal of the system. Role is coupled with responsibilities and constraints. Each role entails responsibilities that are fulfilled by agents playing the role and there are certain constraints that need to be followed when fulfilling the responsibilities towards the accomplishment of a goal.

In the crime modelling, it consists of criminal, police officer, economy sector and civilians. The economy sector is 
modelled as an actor in this case study as they are determining the employee rate of the entire places. The example of criminal role model is shown in Table 1.

Table 1. The role model for criminal

\begin{tabular}{cc}
\hline Role name & Criminal \\
\hline Description & $\begin{array}{c}\text { The people who are jobless and } \\
\text { looking for victim to commit crime }\end{array}$ \\
\hline Responsibiliti & $\begin{array}{c}\text { Travel around the city and } \\
\text { es }\end{array}$ \\
\hline Commit crimes. \\
$\begin{array}{c}\text { Does not commit crime when } \\
\text { police is around. }\end{array}$ \\
\hline
\end{tabular}

Organization model:

Organization model shows the relationship between roles. As for the crime modeling, police arrest criminal and protects civilians.

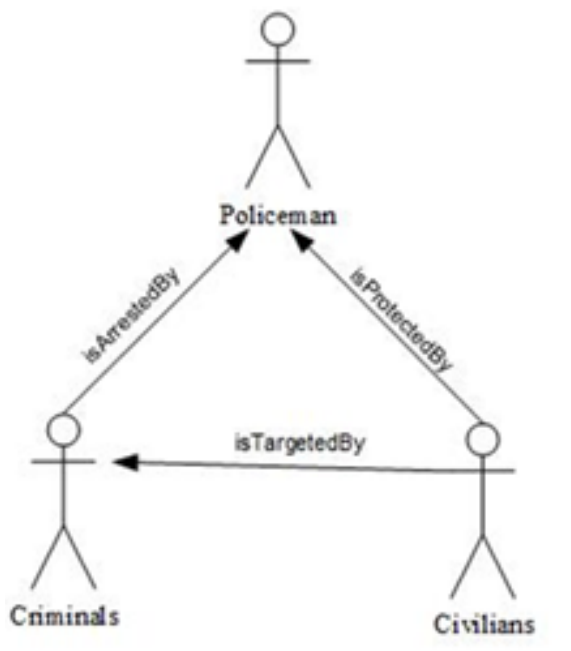

Fig. 2. Organization model for crime model

Crime can be an extremely complex event which consists of a lot of uncertain factors. The domain model for this study is presented in Fig. 3. The domain model represents the information that is handled by the system as a set of domain entities and the relationships between them.

In crime handling, they are four important domain entities. They are the domain entities of 'crime', 'factor', 'daily activity' and 'belonging'. Crime happening in daily activity. Civilian own belonging when involve in daily activity. They are several factors that lead to crime. For example, low employment rates; sickness etc.

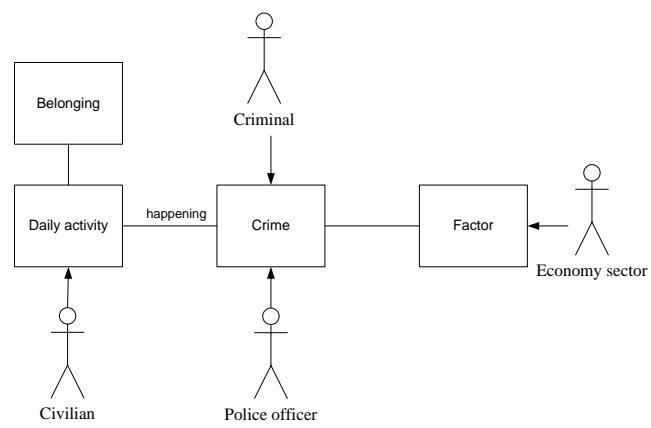

Fig. 3. Domain model for crime handling

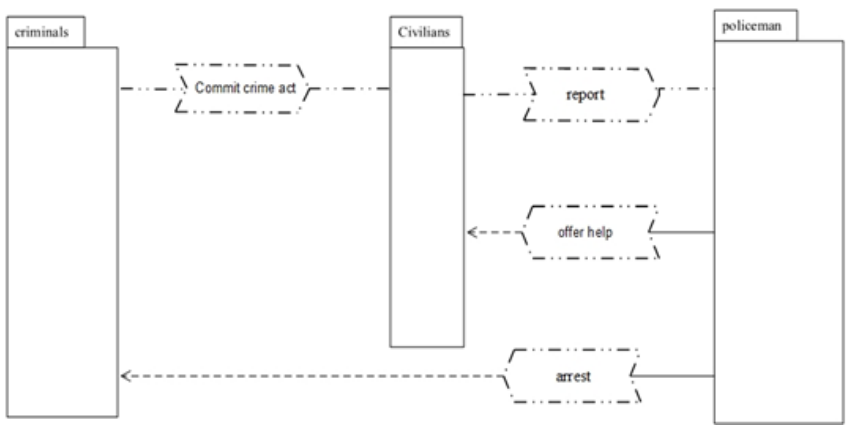

Fig. 4. Interaction model for crime handling

Fig. 4 shown the interaction model for crime handling. An interaction model models the social influence between agents. In this model, interactions between agents are represented through message passing. The interaction model models the content and order of the messages to be exchanged. Here, the criminal agent has committed to crime. The crime handling is designed with a placement of more police officer after receiving the report of claim by the civilian. On the other hand, Fig. 5 presents the behavior model for handling crime. A behavior model indicates what individual agents of a type do. It enables both proactive and reactive behavior to be modelled. An agent achieves a goal through performing activities. The sequence of activities is modelled by means of control flows. A rule is the basic behavior modelling construct. The triggering of a rule happens due to an activity start event, conditions that have been fulfilled, or an action event caused by external agents. The execution of an activity is modelled by triggering a rule to update the agent's mental state and/or send the message or perform an action of another type by an individual agent. An agent is proactive if its mental state can trigger an activity. An agent reacts due to the perception received through a communication action or physical action by a human agent. A communication action involves exchanging messages between agents. A physical action involves a direct command by a human, which normally occurs through a graphical user interface. In the crime modelling, we model the details behavior of PoliceOfficeAgent in handling the crime.

In this section, we presented the agent modelling for crime handling. In the following section, we present the runtime model through netlogo. We transform the agent models (e.g. goal model, role model etc.) into the netlogo through the proposed guideline by the author.

\section{SIMULATION}

The section presents the simulation results by transforming the agent models into netlogo [17], [18]. Setting up Unigarden, Kota Samarahan as our primary environment, we have the police, civilians, criminal agents in place for our simulation model. With the simulation model, a crime rate threshold (danger-level) can be set (refer Fig. 6). When the crime reported is more than the threshold, more police will be deployed in the area to deter crime. Crime rate for the 
simulation is observed with different parameters set on the police agents.

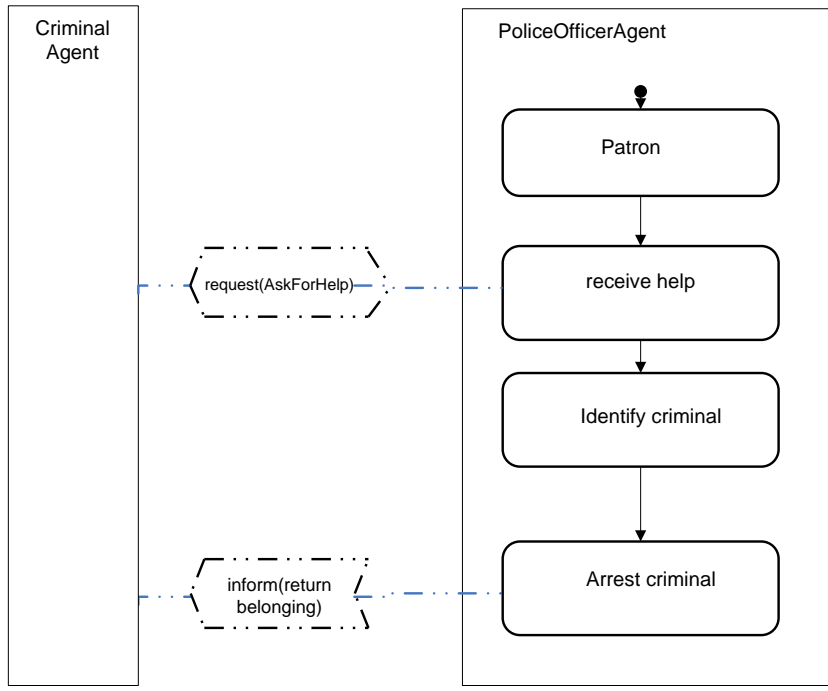

Fig. 5. Behavior model for handling crime
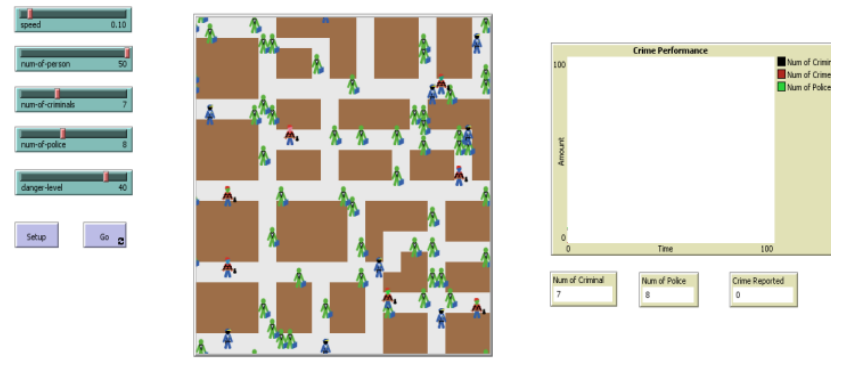

Fig. 6. Presents the interface of Scenario 1 simulation

Refer to Fig. 6, we have an environment simulated to mimic the actual structural design of the neighborhood in Unigarden. There will be no any means of transportation in the simulation. Brown blocks represent the building and obstacle in Unigarden. Slider bar (num-of-person) represents the number of civilians live in the area, (num-of-criminal) represents the number of criminals in the area and num-of-police represents the number of police assigned to patrol around the neighborhood. Danger-level slider bar is a threshold limit set to reinforce police to deter crime in the area whenever the crime reported exceeded the threshold. The speed slider bar is used to control the speed of overall simulation.

Result observation 1 (without enforcement officer like police):

For the first run of the simulation, we set the civilian number to 50,3 criminals and 0 police. Based on the simulation run, the result shows that crime reported in the area is climbing up fast. Referring to Fig. 7, it shows that when there are no police, there is 20 crimes reported in just 152 ticks. The crime reported goes up drastically without police presence. At just 671 ticks, there is 46 crimes reported. From the observation, we can conclude that when there is no police presence, the crime rate will increase drastically.

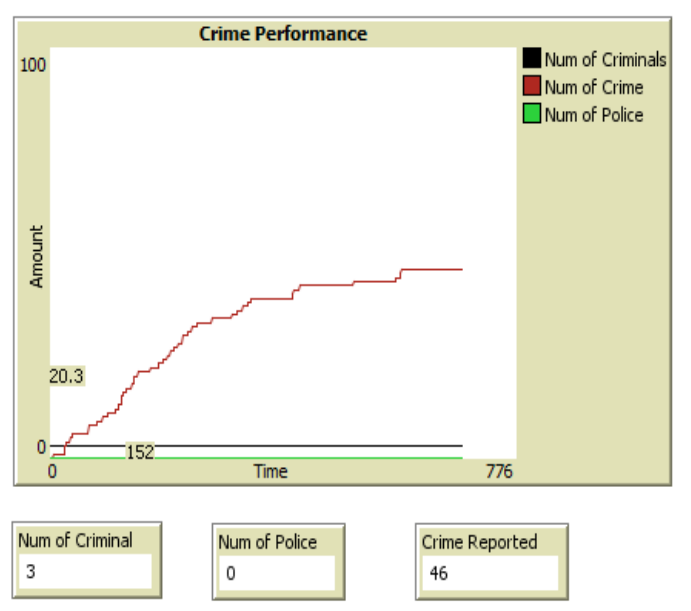

Fig. 7. Simulation results with no police

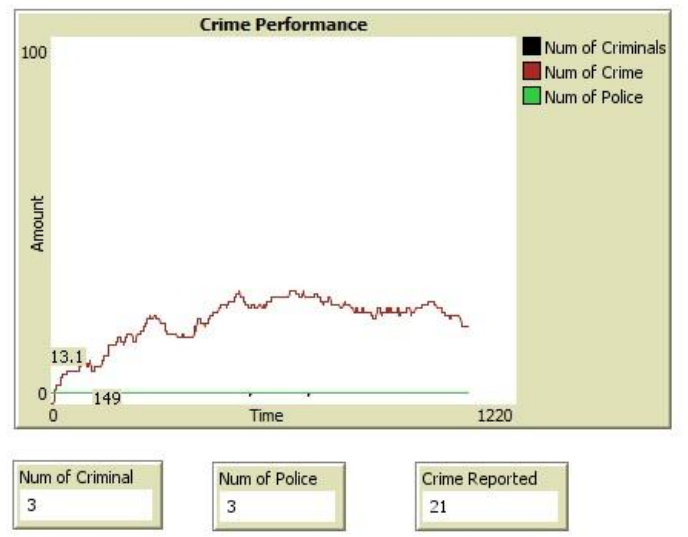

Fig. 8. Simulation results with low number of police

We continue the simulation with increasing the number of police. Overall, the simulation lead to the following observations. Overall observation is shown in following table. From the results above, we can make an inference that the number of police can affect the crime rates area. A crime model is presented in the previous experiment. Work has been done to extend the model by studying the effort of unemployment rate towards crime. The overall results of crime rate versus unemployment rate is shown in Table 3.

Table 2. The observation for scenario 1 with different parameter setting

\begin{tabular}{cccc}
\hline Experim & $\begin{array}{c}\text { No. of } \\
\text { ent }\end{array}$ & $\begin{array}{c}\text { No. of } \\
\text { Criminal } \\
\text { assigned }\end{array}$ & Observations \\
& $\begin{array}{c}\text { No } \\
\text { police } \\
(0)\end{array}$ & 3 & $\begin{array}{c}\text { Crime rate climbs } \\
\text { up at very fast rate. }\end{array}$ \\
\cline { 2 - 4 } 1 Scenario & $\begin{array}{c}\text { Less } \\
\text { Police (3) }\end{array}$ & 3 & $\begin{array}{c}\text { Crime rate goes } \\
\text { up at lower speed }\end{array}$ \\
\cline { 2 - 4 } & $\begin{array}{c}\text { More } \\
\text { police } \\
(10)\end{array}$ & 5 & $\begin{array}{c}\text { Crime rate goes } \\
\text { uplowly and } \\
\text { reduced at times }\end{array}$ \\
\hline
\end{tabular}


Table 3. The observation for scenario 2 with different parameter setting

\begin{tabular}{cccc}
\hline \multirow{2}{*}{$\begin{array}{c}\text { Experim } \\
\text { ent }\end{array}$} & $\begin{array}{c}\text { No. of } \\
\text { Police } \\
\text { assigned }\end{array}$ & $\begin{array}{c}\text { No. of } \\
\text { Criminal }\end{array}$ & Observations \\
\hline \multirow{3}{*}{$\begin{array}{c}\text { No } \\
\text { Solice } \\
\text { Scenario }\end{array}$} & 3 & $\begin{array}{c}\text { Crime rate climbs } \\
\text { up at very fast rate. }\end{array}$ \\
\cline { 2 - 5 } & $\begin{array}{c}\text { Less } \\
\text { Police (3) }\end{array}$ & 3 & $\begin{array}{c}\text { Crime rate goes } \\
\text { up at lower speed }\end{array}$ \\
\cline { 2 - 4 } & $\begin{array}{c}\text { More } \\
\text { police } \\
(10)\end{array}$ & 5 & $\begin{array}{c}\text { Crime rate goes } \\
\text { uplowly and } \\
\text { reduced at times }\end{array}$ \\
\hline
\end{tabular}

\section{MODEL VALIDATION\& RESULTS}

Validation of the models and simulation result is a vital part of this whole study. It measures how well the model reflects the real-world scenario as the main point of this $\mathrm{AOM}$ is to model the real-world environment. To increase the credibility of the model, we ran the model repeatedly with different parameter and used the outcome to evaluate the veracity of the model. With the consistent result, it is used to compare with others related work which served as a guideline in the calibration of our model. The aim of our study was to verify the correctness of agent models (e.g. goal model, domain model, behavior model, knowledge model, interaction model) and at the same time to investigate the adoption of AOM in crime domain. The descriptive output validation was used to calibrate the model. The validation of our model uses existing empirical data as a guideline. By comparing to existing real-world statistics, the outputs of the simulation results show similar pattern with others work [29]. From the research, they showed the relationship between the number of police and the crime rate. The number of crimes in their research area declines as the number of police increases as shown in Fig. 9.
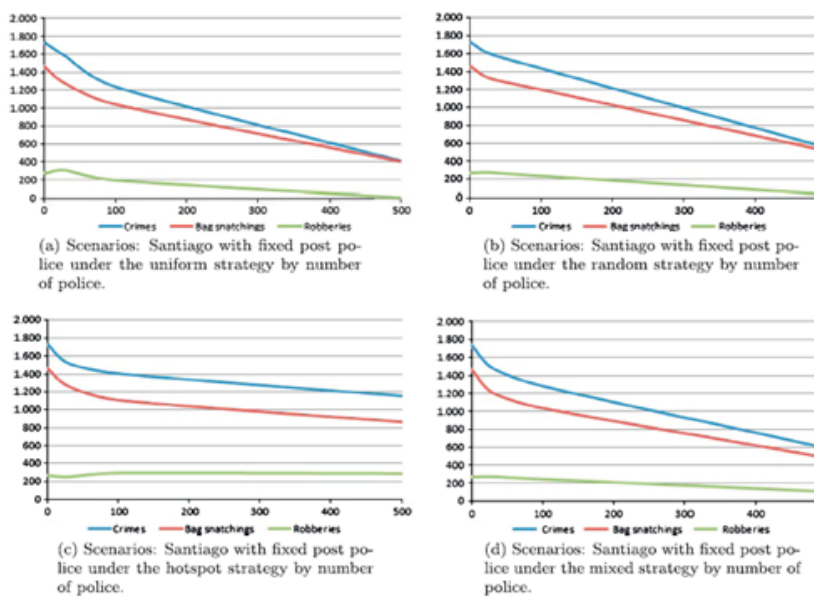

Fig. 9. Simulation results from [29] on relationship between number of crimes in Santiago against number of polices deployed.

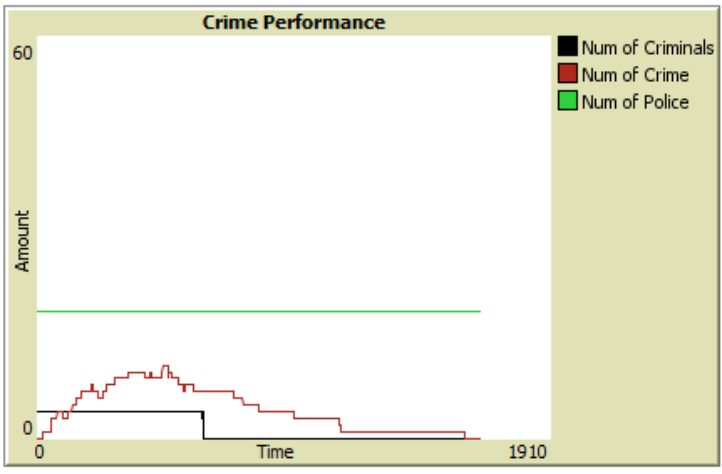

Fig. 10. Simulation result with high number of police

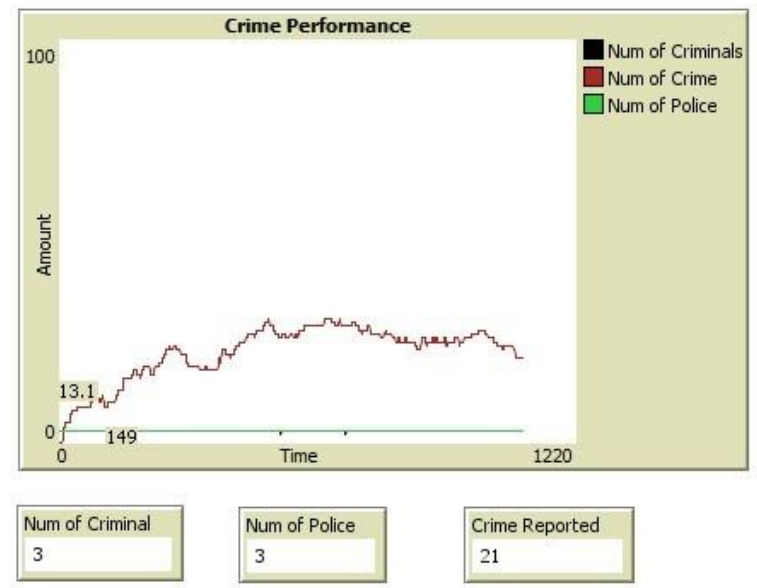

Fig. 11. Simulation result with low number of police

By comparing the result from [29] with our simulation results, we found that both results share the same characteristics. From the analysis, we can see that with high number of police (Fig. 10), crime number is decreasing Meanwhile, with low number of police (Fig. 11), the crime number is increasing in both simulation results. This proved our hypothesis that the number of police will impact the crime rate in the study area. Also, with the provided data and comparison, it is sufficient to support and validate the presented AOM simulation model.

To further validate our simulation, we compare our simulation result with national crime data from Canada as shown in [30]. We compared result from scenario 2 and the national crime statistic in Canada. From the comparison, both results (Fig. 12) share the similar pattern which suggested that high unemployment increases crime rate in the area. In another words, high unemployment rate is one of the factors that causing high crime rate in which it achieved one of the sub goal in our proposed goal model (identify crime factors). Hence, with the matching pattern of our comparison, this simulation is considered as validated. 

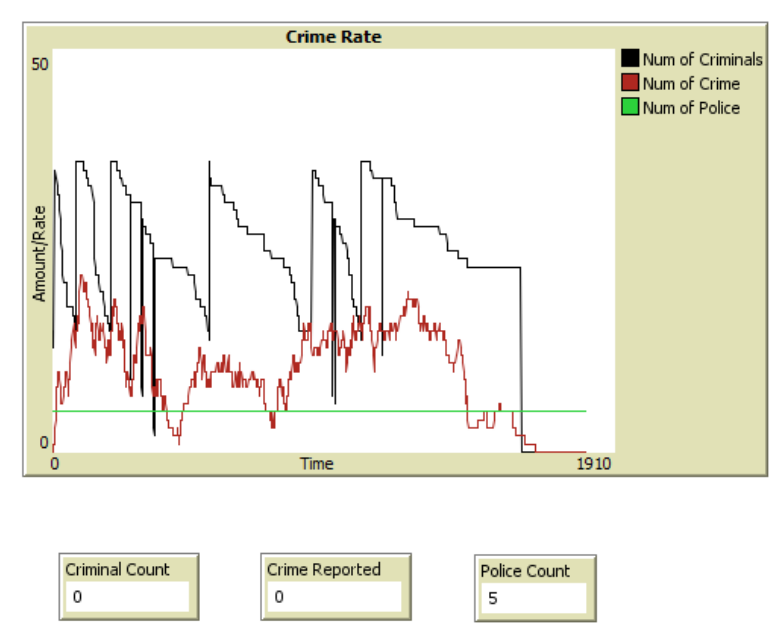

Fig. 12. Shows simulation result from scenario 2. (High unemployment rate)

\section{LESSON LEARNT}

Agent Oriented Methodology (AOM) is relatively a new modeling paradigm and has spurred a considerable amount of interests. Its unique characteristic is that an agent is an independent component of a system which can interact with other agents and its environment to achieve goals. In this manner, large systems of agents can be created to mimic real environments. The agents can have behavioral information built in to determine how they should achieve their goals. An accurate agent-oriented model which incorporates human behavioral factors as well as detailed environmental components could have a number of uses. In the field of crime modeling, not only could it be used to analyze the reasons offenders travel to certain areas but also provide "what if" analyses. These could include considerations such as the effect that new environmental developments or crime reduction initiatives might have on a local area before their implementation.

\section{SUMMARY}

Agent oriented methodology (AOM) is useful to model a complex socio technical system. In this paper, we presented how crime study can be modelled through goal model, role model, organization model, domain model, interaction model, behavior model and transform into netlogo for agent-based simulation. As crime simulation is complex study, we demonstrate how the study can be modelled in a systematic manner with a walkthrough case study in this paper. While having a methodology can guide the development of simulation model, time and efforts are required to understand the domain prior simulation. Hence, it may delay the simulation process. In future, more works are needed to investigate the adoption of agent-oriented model in complex crime model. Meanwhile, validation of the agent models is needed.

\section{REFERENCES}

1. Iglesias, Carlos A., Mercedes Garijo, and José C. González, “A survey of agent-oriented methodologies," in International Workshop on Agent Theories, Architectures, and Languages, Springer, Berlin, Heidelberg, 1998, pp. 317-330.

2. Bernon, Carole, Massimo Cossentino, and Juan Pavón, "Agent-oriented software engineering," The Knowledge Engineering Review 20, no. 2 ,2005, pp. 99-116.
3. Xinjun, Mao, Chang Zhiming, Wang Ji, and Wang Huaimin, "Agent-oriented software engineering: status and challenges [J]," Journal of Computer Research and Development 10, 2006.

4. Shiang, CheahWai, Alfian Abdul Halin, Marlene Lu, and Gary CheeWhye, "Long Lamai community ICT4D e-commerce system modelling: an agent oriented role-based approach," The Electronic Journal of Information Systems in Developing Countries 75, no. 1, 2016, pp. 1-22.

5. WaiShiang, Cheah, Bong TienOnn, Fu Swee Tee, Muhammad Asyraf bin Khairuddin, and MsuryMahunnah, "Developing agent-oriented video surveillance system through agent-oriented methodology (AOM)," Journal of computing and information technology 24, no. 4, 2016, pp. 349-368.

6. Shiang, CheahWai, John-Jules Meyer, and KuldarTaveter, "Agent-oriented methodology for designing cognitive agents for serious Games," Engineering Multi-Agent Systems 39, 2016.

7. Cheah, WaiShiang, Edwin Mit, and Marlene ValeriAiSiok Marlene ValeriAiSiok, "Designing a shared single display education application through interactive patterns," Journal of Software Engineering and Applications 7, no. 13, 2014, pp. 1074.

8. WaiShiang, Cheah, SimYeeWai, Shane Nizam, and LohCheeWyai, "Agent oriented requirement engineering for lake mathematical modelling: preliminary study," Journal of Telecommunication, Electronic and Computer Engineering (JTEC) 8, no. 2, 2016, pp. 5-10.

9. WaiShiang, Cheah, Shane Nissom, SimSiong Fong, and Muhammad AsyrafKhairuddin, "Chemistry modelling and simulation through agent oriented modelling and Netlogo," Journal of Telecommunication, Electronic and Computer Engineering (JTEC) 9, no. 2-10, 2017, pp. 145-149.

10. Cheah, WaiShiang, Shane Nissom, Jane Labadin, NurfauzaJali, and HuiKeng Lau, "When requirement engineering meets computational science modelling and simulation," Advanced Science Letters 23, no. 11, 2017, 11288-11292.

11. Paay, Jeni, Leon Sterling, Sonja Pedell, Frank Vetere, and Steve Howard, "Interdisciplinary design teams translating ethnographic field data into design models: communicating ambiguous concepts using quality goals," in Innovative Methods, User-Friendly Tools, Coding, and Design Approaches in People-Oriented Programming, IGI Global, 2018, pp. 226-261.

12. Sterling, Leon, Alex Lopez-Lorca, and MaheswareeKissoon-Curumsing, "Adding emotions to models in a viewpoint modelling framework from agent-oriented software engineering: a case study with emergency alarms," in Innovative Methods, User-Friendly Tools, Coding, and Design Approaches in People-Oriented Programming, IGI Global, 2018, pp. 324-367.

13. Sterling, Leon, and Thomas Juan, "The software engineering of agent-based intelligent adaptive systems," in Proceedings of the 27 th international conference on Software engineering, ACM, 2005, pp. 704-705.

14. Ronald, Nicole, Leon Sterling, and Michael Kirley, "An agent-based approach to modelling pedestrian behaviour," International Journal of Simulation 8, no. 1, 2007, pp. 25-38.

15. Miller, Tim, Sonja Pedell, Antonio A. Lopez-Lorca, Antonette Mendoza, Leon Sterling, and AlenKeirnan, "Emotion-led modelling for people-oriented requirements engineering: the case study of emergency systems," Journal of Systems and Software 105, 2015, pp. 54-71.

16. Marshall, James, "Agent-based modelling of emotional goals in digital media design projects," in Innovative Methods, User-Friendly Tools, Coding, and Design Approaches in People-Oriented Programming, IGI Global, 2018, pp. 262-284.

17. Railsback, Steven F., Steven L. Lytinen, and Stephen K. Jackson, "Agent-based simulation platforms: review and development recommendations," Simulation 82, no. 9, 2006, pp. 609-623.

18. Hamill, Lynne, "Agent-based modelling: the next 15 years," Journal of Artificial Societies and Social Simulation 13, no. 4, 2010,pp. 7.

19. Zambonelli, Franco, and Andrea Omicini, "Challenges and research directions in agent-oriented software engineering," Autonomous agents and multi-agent systems 9, no. 3, 2004, pp. 253-283. 
20. Jennings, Nicholas R, "On agent-based software engineering," Artificial intelligence 117, no. 2, 2000, pp. 277-296.

21. Brantingham, P. L., and E. R. Groff, "The future of agent-based simulation in environmental criminology," American Society of Criminology, Nashville, TN, 2004.

22. Short, Martin B., Maria R. D'orsogna, Virginia B. Pasour, George E. Tita, Paul J. Brantingham, Andrea L. Bertozzi, and Lincoln B. Chayes, "A statistical model of criminal behavior," Mathematical Models and Methods in Applied Sciences 18, no. supp01, 2008, pp. 1249-1267.

23. Wilson, James Q., and George L. Kelling, "The police and neighborhood safety: broken windows," Atlantic monthly 127 no. 2,1982 , pp. 29-38.

24. Birks, Daniel, Michael Townsley, and Anna Stewart, "Generative explanations of crime: using simulation to test criminological theory," Criminology 50, no. 1, 2012, pp. 221-254.

25. Cohen, Lawrence E., and Marcus Felson, "Social change and crime rate trends: a routine activity approach," American sociological review, 1979, pp. 588-608.

26. Groff, Elizabeth, and Dan Birks, "Simulating crime prevention strategies: a look at the possibilities," Policing: A journal of Policy and Practice 2, no. 2, 2008, pp. 175-184.

27. Melo, Adriano, MaironBelchior, and Vasco Furtado, “Analyzing police patrol routes by simulating the physical reorganization of agents," in International Workshop on Multi-Agent Systems and Agent-Based Simulation, Springer, Berlin, Heidelberg, 2005, pp. 99-114.

28. Sterling, Leon, and KuldarTaveter, Art of Agent-oriented Modeling (Intelligent Robotics and Autonomous Agents). MIT Press, 2009.

29. Devia, Nelson, and Richard Weber, "Generating crime data using agent-based simulation," Computers, Environment and Urban Systems 42, 2013, pp. 26-41.

30. Janko, Zuzana, and GurleenPopli, "Examining the link between crime and unemployment: a time-series analysis for Canada," Applied Economics 47, no. 37, 2015, 4007-4019.

\section{AUTHORS PROFILE}

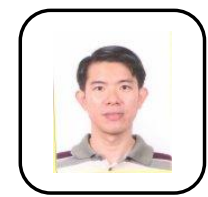

CheahWaiShiangis a senior lecturer from Faculty of Computer Science \& IT, UNIMAS. He graduated with $\mathrm{PhD}$ in software engineering, The Melbourne University. His research is agent oriented modelling and simulation.

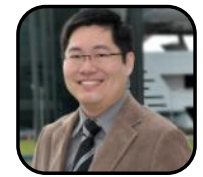

Sim YeeWaiis currently serving as an Associate Professor at School of Computing and Creative Media, University College of Technology Sarawak. He graduated with a $\mathrm{PhD}$ degree, awarded by University of Southampton in 2004. His research interests are in the areas of agent modelling and simulation, machine learning and knowledge management

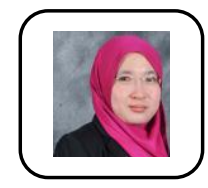

NurfauzabtJaliis a lecturer at Faculty of Computer Science and Information Technology, UNIMAS. She received her $\mathrm{MSc}$ in Science Computer at UniversitiTeknologi Malaysia (UTM). Her research interest in the area of Software Engineering.

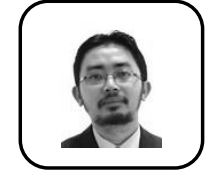

Muhammad Asyraf bin Khairuddinis a lecture from Faculty of Computer Science \& IT, UNIMAS. He is currently pursuing his $\mathrm{PhD}$ in Software Engineering at Universiti Putra Malaysia. His research interests include requirement engineering and requirement elicitation. 